\title{
A Legalização do Abortamento no Discurso do Jornal Folha de São Paulo (2011-2014)
}

\author{
Thiago Mikael-Silva ${ }^{1}$ \\ Faculdade Ciências da Vida, Sete Lagoas, MG, Brasil \\ Alberto Mesaque Martins \\ Departamento de Psicologia da Universidade Federal de Minas Gerais, \\ Belo Horizonte, MG, Brasil
}

\begin{abstract}
Resumo
O estudo teve como objetivo analisar os discursos sobre a legalização e descriminalização do abortamento veiculados pela mídia impressa brasileira. Com base na perspectiva francesa da Análise do discurso, foram analisadas matérias publicadas entre o período de 2011 a Agosto de 2014 pelo Jornal Folha de São Paulo. Os resultados sugerem que a expressão da aparição da legalização do aborto nos discursos veiculados nas matérias do corpus construído possui possível relação com nuances dos contextos em voga. O ano de 2011, que sucedia a campanha eleitoral para a presidência, contou com tentativas de silenciamento do tema; já o ano de 2012 foi marcado pela liberação do aborto nos casos de anencefalia, contribuindo para o deslocamento do tema para a ótica da Saúde Pública que foi fortalecida no ano de 2013 com o apoio do Conselho Federal de Medicina (CFM). O primeiro semestre de 2014 caracterizou-se pela esquiva dos principais candidatos nas eleições presidenciais. Foram identificados discursos religiosos, sanitários, feministas, midiáticos e eleitoreiros. Buscou-se contribuir para a discussão sobre a legalização do aborto no Brasil, sendo necessário refletir sobre o veículo midiático e sua capacidade de legitimação de uma prática que causa controvérsia, mas tem aceitação quando ocorre de modo silencioso e invisível.
\end{abstract}

Palavras-chave: Aborto, Análise do Discurso, meios de comunicação de massa, Saúde Pública.

\section{The Legalization of Abortion in the Discourse of the Newspapper Folha de São Paulo (2011-2014)}

\begin{abstract}
This study is aimed to analyze the discourses about the legalization and decriminalization of abortion conveyed by Brazilian print media. On the basis of French perspective of discourse analysis, it was analyzed in the news, published between the periods of January 2011 to August 2014 in the newspapers, Folha de São Paulo. The results suggest that divulgation of the theme legalization of abortion has a relationship with shade in contexts of anger. In year 2011, after election campaign for the presidency, we observed attempts to silence this theme. The year 2012 was marked by the liberation of abortion in cases of anencephaly, contributing to the dislocation of the theme from the perspective of Public Health. This fact was strengthened in 2013 with the support of the Conselho Federal de Medicina (CFM). The first 6 months of 2014 was characterized as an escape taken by the major candidates during presidential elections. It identifies religious, sanitary, feminists, midiatic and electoralists discourses. This study should
\end{abstract}

Endereço para correspondência: Br 040, km 456, Balaios, Caetanópolis, MG, Brasil 35770-000. Fone: (31) 9923-6233. E-mail: thiagomikhael@hotmail.com e albertomesaque@yahoo.com.br 
contribute to the debate about the legalization of abortion in Brazil, being necessary to reflect about the media tools and its capacity to legitimize a practice that cause controversy, but has acceptance when occurs silently and invisibly.

Keywords: Abortion, Discourse Analysis, mass media, Public Health.

\section{La Legalización del Abortamiento en el Discurso del Periódico Folha de São Paulo (2011-2014)}

\section{Resumen}

El estudio buscó analizar los discursos sobre la legalización y despenalización del aborto en los medios de comunicación impresos brasileños. Desde la perspectiva francesa del Análisis del Discurso, fueron analizadas textos publicados en el periódico Folha de São Paulo, en el período de 2011 a agosto de 2014. Los resultados sugieren que la expresión de la aparición de la legalización del aborto tiene una posible relación con matices del contexto en cuestión. El año 2011 ha sucedido la campaña electoral para la presidencia, tuvo intentos de silenciar el tema; el año 2012 estuvo marcado por la liberación del aborto en casos de anencefalia, contribuyendo con lo cambio del tema a la perspectiva de la salud pública que se fortaleció en 2013 con el apoyo de Conselho Federal de Medicina (CFM). El primer semestre de 2014 se caracterizó por la evitación del tema por los principales candidatos en las elecciones presidenciales. Se identificaron los discursos religiosos, sanitarios feministas, mediáticos y electorales. Hemos tratado de contribuir a la discusión sobre la legalización del aborto en Brasil, siendo necesario reflexionar sobre los medios de comunicación y su capacidad de legitimación de una práctica que causa controversia, pero tiene la aceptación cuando ocurre de manera silenciosa y invisible.

Palabras clave: Aborto, Análisis de Discurso, medios de comunicación de masa, Salud Pública

$\mathrm{Na}$ atualidade, o abortamento inseguro representa um problema de Saúde Pública, sobretudo, nos países da América Latina nos quais, frequentemente, a criminalização não impede sua prática (Soares, Galli, \& Viana, 2011). No Brasil, a Pesquisa Nacional de Aborto (PNA) indica que, até os 40 anos, mais de uma em cada cinco mulheres da área urbana recorrem ao abortamento, sendo que o número estimado de abortos anuais no país beira 1,4 milhões, resultando em grandes gastos para os cofres públicos (Bursztyn, Tura, \& Correa, 2009; Diniz \& Medeiros, 2010). Ainda nessa direção, o abortamento inseguro apresenta-se entre as cinco principais causas de mortalidade materna, além de resultar em complicações físicas e psicossociais pós-abortamento (Ministério da Saúde, 2009).

No Brasil a prática do aborto remonta o período colonial e, até 1830 , era tratada como uma conduta faltosa, sendo que, após esse período, passou a configurar como crime com punições previstas apenas aos terceiros que o praticassem (Castelbajac, 2010; Mikael-Silva \& Martins,
2015). Somente no Código Penal (CP) de 1890 o auto-aborto foi penalizado, com atenuantes, caso fosse realizado para ocultar a desonra. Com a mudança do paradigma da honra para o paradigma biopolítico, observam-se também mudanças na legislação sobre o aborto, de modo que o CP de 1940, ainda vigente, trouxe permissões legais apenas para os casos onde fosse constatado risco a vida da gestante, como também, em situações de gravidez resultante de estupro (Hentz, 2013; Mikael-Silva \& Martins, 2015).

Nas décadas de 1970 e 1980 os movimentos sociais de mulheres e feministas se empenharam na legalização do abortamento com base nos direitos sexuais e reprodutivos, alicerçados no princípio da autonomia (Bursztyn et al., 2009). O debate sobre o direito ao abortamento foi se espalhando e agregando novas instâncias e atores sociais permitindo que alguns posicionamentos tradicionais como, por exemplo, "pró-escolha" e "pró-vida" fossem consolidados e afirmados por grupos distintos da sociedade, instaurando um debate controverso sobre a legalização do abor- 
tamento (Hentz, 2013; Mikael-Silva \& Martins, 2015).

Uma dessas instâncias é a mídia, na qual o tema do aborto aciona seus instrumentos narrativos de produção de notícias. Nesse sentido, a mídia funciona como veículo de (re)produção de discursos capazes de atingir públicos variados, cuja influência se desdobra até na agenda política nacional (Gregolin, 2008). Embora a discussão acerca do papel da mídia na difusão de discursos sobre o abortamento seja uma temática ainda incipiente na literatura nacional, os estudos existentes apontam para uma hegemonia do tratamento da questão sob o dilema moral (Diniz \& Castro, 2011; Fontes, 2012; Pinho, 2009). Essas concepções morais podem repercutir no deslocamento do tema para a ótica da saúde pública.

Considerando que o discurso é uma prática social e que os enunciados que o compõem podem ser considerados correlatos de uma posição histórico-social (Foucault, 1969/2008; Maingueneau, 1997), é possível esperar que o tema da legalização do abortamento apareça no discurso da mídia, tomada aqui como (re)produtora de discursos provenientes de contextos, instituições e atores diversos (Gregolin, 2008). Assim, este estudo teve como objetivo analisar

Tabela 1

Matérias Selecionadas na Versão Online do Jornal Folha de São Paulo Veiculadas nos Anos de 2011, 2012, 2013 e 2014

\begin{tabular}{llr}
\hline $\mathbf{N}^{\circ}$ & \multicolumn{1}{c}{ Título das matérias } & Data \\
\hline 01 & Arcebispo de Brasília comandará um dos 'ministérios' do Vaticano & $05 / 01 / 2011$ \\
02 & Novo Congresso vai encarar velhas polêmicas & $30 / 01 / 2011$ \\
03 & CNBB evita discutir aborto em 1 ${ }^{\text {encontro com Dilma }}$ & $17 / 02 / 2011$ \\
04 & Religiosos defendem legalização do aborto na Argentina & $31 / 05 / 2011$ \\
05 & Movimento critica projetos contrários a interesses femininos & $18 / 08 / 2011$ \\
06 & DEM mira valores conservadores para repor perdas para o PSD & $29 / 09 / 2011$ \\
07 & América Latina deve respeitar direitos das mulheres, diz ONG & $29 / 09 / 2011$ \\
08 & Eleitores do Mississipi decidem na terça sobre criminalização do aborto & $05 / 11 / 2011$ \\
09 & Falha de organização gera saia justa para Dilma em evento & $12 / 12 / 2011$ \\
10 & Mulheres discutem aborto e diversidade sexual em evento em Brasília & $13 / 12 / 2011$ \\
11 & Senado do Uruguai discute hoje sobre descriminalização do aborto & $27 / 12 / 2011$ \\
12 & Senado do Uruguai aprova legalização do aborto; Câmara ainda votará & $27 / 12 / 2011$ \\
13 & Supremo enfrentará pauta polêmica em 2012 & $01 / 01 / 2012$ \\
14 & Partidos tentam evitar veto de igrejas em São Paulo & $16 / 01 / 2012$ \\
15 & Nova ministra de Dilma diz que aborto não é questão ideológica & $07 / 02 / 2012$ \\
\hline
\end{tabular}

os discursos sobre a legalização e descriminalização do abortamento veiculados pela mídia impressa brasileira.

\section{Metodologia}

Visando analisar os discursos sobre a legalização e descriminalização do abortamento, veiculados pela mídia, realizou-se um estudo qualitativo e documental. Por meio dos termos "legalização do aborto", "descriminalização do aborto", "criminalização do aborto", "legalização do abortamento", "descriminalização do abortamento" e "criminalização do abortamento" buscou-se matérias jornalísticas veiculadas pela versão online do Jornal Folha de São Paulo - um dos periódicos de maior circulação no Brasil - entre o período janeiro de 2011 a agosto de 2014 que discutissem a temática da legalização do abortamento.

Na primeira etapa foram encontradas 152 matérias, as quais foram submetidas, posteriormente, a uma leitura preliminar a fim de selecionar apenas os textos que tivessem a "legalização do aborto" como tema central. Esse critério viabilizou a exclusão de 95 matérias, restando assim, 57 textos que foram selecionados para construção do corpus de análise (Tabela 1). 


\begin{tabular}{|c|c|c|}
\hline $\mathrm{N}^{\circ}$ & Título das matérias & Data \\
\hline 16 & Deputado do PMDB critica nova ministra da Secretaria das Mulheres & $09 / 02 / 2012$ \\
\hline 17 & Dilma diz que nova ministra atuará 'segundo diretrizes do governo' & $10 / 02 / 2012$ \\
\hline 18 & Questão moral do aborto é religiosa em país laico, diz leitor & $12 / 02 / 2012$ \\
\hline 19 & CNBB diz que posição de nova ministra sobre aborto 'incomodou' & $16 / 02 / 2012$ \\
\hline 20 & Padre Marcelo defende mobilização de setores contra nova ministra & $27 / 02 / 2012$ \\
\hline 21 & Religiosos voltarão a circular panfletos antiaborto em São Paulo & $10 / 03 / 2012$ \\
\hline 22 & Justiça da Argentina aprova aborto para casos de estupro & $13 / 03 / 2012$ \\
\hline 23 & Católicos antiaborto voltam a distribuir panfleto contra PT em SP & $21 / 03 / 2012$ \\
\hline 24 & Espanha retomará lei de 30 anos atrás sobre aborto, diz ministro & $05 / 04 / 2012$ \\
\hline 25 & STF marca para 11 de abril julgamento sobre aborto de anencéfalos & $23 / 03 / 2012$ \\
\hline 26 & Julgamento sobre aborto de anencéfalos será divisor de águas, diz ministro & $10 / 04 / 2012$ \\
\hline 27 & Grávida de anencéfalo tem direito de não sofrer, diz procuradora & $11 / 04 / 2012$ \\
\hline 28 & Juristas católicos pedem que Senado não legalize aborto e eutanásia & 03/08/2012 \\
\hline 29 & Nuas, uruguaias protestam contra falhas de projeto que descriminaliza aborto & $25 / 09 / 2012$ \\
\hline 30 & Deputados uruguaios aprovam projeto de lei que descriminaliza o aborto & $26 / 09 / 2012$ \\
\hline 31 & Pastor pede voto para vereador durante culto & $08 / 10 / 2012$ \\
\hline 32 & Uruguai aprova aborto para gestações de até 12 semanas & $17 / 10 / 2012$ \\
\hline 33 & Candidatos voltam a exibir divergências na disputa pela $\mathrm{OAB}$ & $27 / 11 / 2012$ \\
\hline 34 & Protestos marcam primeiro dia de descriminalização do aborto no Uruguai & $03 / 12 / 2012$ \\
\hline 35 & Em El Salvador, mulheres podem ser presas por ter aborto espontâneo & $22 / 10 / 2013$ \\
\hline 36 & Estados limitam aborto nos EUA 40 anos após liberação & $22 / 01 / 2013$ \\
\hline 37 & Maioria dos americanos apoia aborto com restrições & $22 / 01 / 2013$ \\
\hline 38 & Legalizar aborto na $12^{\mathrm{a}}$ semana 'deseduca' e é 'grave', diz bispo & $21 / 03 / 2013$ \\
\hline 39 & Uruguai poderá debater lei de aborto com viabilização de referendo & $21 / 03 / 2013$ \\
\hline 40 & Regra sobre aborto só deve ser votada no $2^{\circ}$ semestre no Senado & $22 / 03 / 2013$ \\
\hline 41 & Leitores repercutem defesa de médicos ao aborto até $12^{\mathrm{a}}$ semana & $23 / 03 / 2013$ \\
\hline 42 & Deputados e senadores tentam barrar descriminalização do aborto & $26 / 03 / 2013$ \\
\hline 43 & Leitores comentam a questão do aborto no Brasil & $30 / 03 / 2013$ \\
\hline 44 & Silas Malafaia: Marco Feliciano é a bola da vez & $05 / 04 / 2013$ \\
\hline 45 & Dilma foge de polêmica para manter paz com evangélicos & $15 / 04 / 2013$ \\
\hline 46 & Leitora critica inação do governo diante de clínicas que fazem aborto & $09 / 05 / 2013$ \\
\hline 47 & Evangélicos fazem protesto contra o aborto e o casamento gay no DF & $05 / 06 / 2013$ \\
\hline 48 & Protesto contra estatuto do nascituro reúne 1.500 pessoas na praça da Sé, em SP & $15 / 06 / 2013$ \\
\hline 49 & Feministas protestam contra violência sexual ao lado de peregrinos da JMJ & $27 / 07 / 2013$ \\
\hline 50 & Marcha das Vadias critica Igreja Católica em Copacabana, no Rio; assista & $28 / 07 / 2013$ \\
\hline 51 & Religiosos reagem com novos projetos à lei que dá garantias para vítima de estupro & $09 / 08 / 2013$ \\
\hline 52 & Manifestação feminista interdita rua Augusta no centro de SP & $31 / 08 / 2013$ \\
\hline 53 & 'Marcha das Vadias' faz passeata em Ribeirão e pede fim da violência & $28 / 09 / 2013$ \\
\hline 54 & Marcha das Vadias quer protesto anual em Ribeirão Preto (SP) & $30 / 09 / 2013$ \\
\hline 55 & Papa pede que fiéis não sejam "cristãos de vitrine" & $12 / 10 / 2013$ \\
\hline 56 & Leitores comentam artigos sobre a legalização do aborto & $25 / 04 / 2014$ \\
\hline 57 & Com propostas polêmicas PSOL, lança Luciana Genro à Presidência & $22 / 06 / 2014$ \\
\hline
\end{tabular}


As matérias selecionadas foram analisadas na perspectiva da corrente francesa da Análise do Discurso (AD) que, em síntese, compreende a linguagem como indissociável da constituição social e dos processos histórico-sociais (Brandão, 2009). Diante disso, a AD pode ser definida como “. . . um campo de estudo que oferece ferramentas conceituais para a análise [dos] acontecimentos discursivos, na medida em que toma como objeto de estudos a produção de efeitos de sentido" (Gregolin, 2008, p. 13). Brandão (2009) completa que a $\mathrm{AD}$ não se restringe a uma análise meramente gramatical, considerando os aspectos exteriores à linguagem, assim como os elementos sociais, históricos, ideológicos e culturais que circundam e refletem no discurso.

Em relação aos procedimentos da análise, realizou-se (re)leituras cuidadosas dos textos selecionados, buscando interpretar significados despercebidos e não ditos. Foucault (1969/2008) assinala que, em parte, a $\mathrm{AD}$ se destina a interpretar um "já-dito" que é, simultaneamente, um "não dito". Assim, essa primeira etapa possibilita apreender palavras ou termos repetitivos e possíveis significados latentes os quais mantêm conexão com contextos sócio-históricos específicos que integram sua cena enunciativa e os discursos da qual participam.

Com a identificação dos discursos que a mídia veiculou, procurou-se estudar seus efeitos de sentidos. Conforme relembra Brandão (2009), como ciência da intepretação, a $\mathrm{AD}$ visa compreender o modo de significar do discurso, mas não estagna numa interpretação, e sim a interroga. Assim, o corpus do dispositivo analítico do trabalho foi montado com base nas matérias selecionadas, artigos acadêmicos e notícias, prioritariamente veiculadas em fontes governamentais, as quais foram analisadas indagando-se as condições de sua produção discursiva - quem fala e de qual lugar se fala, já que o que é dito não é dito de qualquer lugar (Brandão, 2009; Foucault, 1969/2008) - as relações de poder, contra quem e quais interesses subjazem os discursos identificados, se inserindo favoráveis ou contrários em meio à cena enunciativa.

\section{Resultados e Discussão}

\section{A Cena Enunciativa dos Discursos sobre a Legalização do Aborto (2011-2014)}

Constata-se uma variação no que se refere ao número de matérias produzidas em cada ano. Embora tenha sido considerado apenas o primeiro semestre, o ano de 2014 foi aquele com menor número de matérias, sendo que, em apenas duas matérias o abortamento aparece como tema central. Comparado aos outros anos, 2011 teve menor quantidade de matérias centrais (12), procedido de 2012 (21) e 2013 (22).

O menor número de matérias que caracterizou o ano de 2011 parece ser reflexo de certas nuances do contexto específico em voga, já que o discurso é (re)produzido por indivíduos situados em lugares, cenários e tempos específicos (Brandão, 2009). Assim, conforme Maingueneau (1997), um texto se inscreve numa cena enunciativa, de modo que a interpretação e descrição de seus enunciados transpõe a simples análise de um autor e do que ele pode ter dito explicita ou implicitamente, para que se determine qual posição todo indivíduo pode e deve ocupar para ser seu sujeito (Foucault, 1969/2008).

É preciso considerar que o período selecionado para estudo refere-se aos anos posteriores as eleições presidenciais de 2010 , as quais contaram com a exploração da posição dos candidatos Dilma Rousseff (Partido dos Trabalhadores PT) e José Serra (Partido da Social Democracia Brasileira - PSDB) sobre a legalização do aborto que, nesse momento, estava inclusa no programa de governo do PT (Machado, 2012). Porém, quando pressionada pelos movimentos de base cristã, sobretudo, católicos e evangélicos, houve comprometimento do governo de Dilma com a não legalização do aborto, modificando inclusive o Programa Nacional de Direitos Humanos 3 (PNDH-3) no qual ela estava inserida.

A matéria $\mathrm{n}^{\circ} 3(17 / 02 / 2011)$, já no próprio título, supõe que no primeiro encontro com a presidente, a Conferência Nacional dos Bispos do Brasil (CNBB) com a qual foi selado acordo, a "poupou" do tema da legalização do aborto. 
O termo "poupar" parece sugerir a clemência da Igreja em não pressioná-la a falar sobre um assunto "constrangedor", um tema "espinhoso" conforme foi veiculado na matéria $n^{\circ} 13$ (01/01/2012).

Deste modo, parece que o ano de 2011 demarca um período de tentativas de silenciamento da temática da legalização do aborto que contou com uma espreita silenciosa por parte dos grupos contrários. Isso pode ser observado no discurso do secretário-geral da CNBB, Dom Dimas Lara Barbosa: "Me parece que esse tema [Legalização do aborto] já foi encerrado [grifo nosso] $d u$ rante a campanha" (Matéria $\mathrm{n}^{\circ} 03,17 / 02 / 2011$ ).

Para o secretário-geral da CNBB a discussão já estava "encerrada", mas observando-se outros acontecimentos nos dois meses posteriores, seu discurso parece dispor de uma tentativa de velamento do assunto. Em março de 2011, os parlamentares "pró-vida" organizaram um café da manhã na Câmara dos Deputados, visando o pré-lançamento da Frente Parlamentar Mista em Defesa da Vida - FPMDV (Movimento Nacional da Cidadania pela Vida - Brasil Sem Aborto, 2011). Assim, a FPMDV foi oficialmente relançada em abril de 2011, tendo por objetivos mobilizar a população brasileira contra a legalização do aborto, barrar projetos com tal intuito e aprovar o projeto denominado Estatuto do Nascituro $^{2}$ (Senado Federal, 2011). Acresce-se, ainda, o fato de que em maio de 2011, a CNBB destinou uma moção de apoio a FPMDV (CNBB, 2011).

Para Maingueneau (2006), o discurso visa convencer instituindo uma cena de enunciação que o legitima. Porém, num debate, dificilmente os integrantes enunciam a partir de suas próprias cenografias, pois sem o controle da enunciação, passam a reagir instantaneamente às circunstâncias imprevisíveis proporcionadas pelos interlocutores. Nessa lógica é que o discurso de silenciamento da CNBB parece operar. Foucault

2 Trata-se de um projeto de lei $\left(\mathrm{n}^{\circ} 478 / 2007\right)$ que prevê proteção integral ao nascituro - um ser humano concebido e ainda não nascido. Para tal, busca-se converter em crime quaisquer tipos de aborto - os legais e até a utilização de embriões em pesquisas científicas -, destinando uma pensão às mulheres que engravidarem por estupro. (1970/1999a) já havia admoestado que alguns discursos são acompanhados de procedimentos de interdição, num jogo em torno do tabu do objeto - cujos limites são mais tênues nos temas da sexualidade. As falas da CNBB excluem a existência de um debate que, na verdade, encontra sustentação na própria organização da FPMDV que, assim como a Folha trata o assunto como "polêmica".

$\mathrm{Na}$ perspectiva foucaultiana (Foucault, 1976/1999b), o discurso de Barbosa pode também ser considerado como repressor. $\mathrm{O}$ autor relembra que a repressão funciona, sobretudo, como condenação ao desaparecimento, injunção ao silêncio, ou afirmação de inexistência, provocando a constatação de não há nada para dizer, ver ou saber.

O ano de 2011 também contou com a quarta edição do movimento da Marcha das Margaridas. No dia seguinte à marcha, as representantes foram recebidas pela Subcomissão Permanente em Defesa da Mulher (SPDM) no Senado, onde apresentaram "críticas" aos projetos contrários aos "interesses femininos". Conforme a secretária nacional da mulher trabalhadora da Central Única dos Trabalhadores (CUT), Rosane Silva, que teve seu discurso reproduzido pela Folha ("Movimento critica projetos", 2011) na matéria n 05 (18/08/2011):

A mulher é obrigada a ser mãe. Nós não temos o direito neste país, hoje, de decidir sobre nosso corpo, de decidir se a gente quer ou não quer ser mãe. E esses projetos que hoje estão em pauta no Congresso Nacional não somente nos criminalizam como levam milhões de mulheres à morte . . .

Ainda que a Folha não tenha especificado, os projetos "contrários aos interesses femininos" são aqueles que visam enrijar a legislação do aborto, como o Estatuto do Nascituro. Nessa época, esse movimento social havia rejeitado projetos no Congresso Nacional, de enquadramento do aborto como crime hediondo; de interdição completa dessa prática e o Estatuto do Nascituro (Congresso Nacional, 2011).

No final de 2011, políticas de enfoque materno-infantil, foram alvos do repúdio dos movimentos feministas. Em parte, é sobre isso que a 
matéria ${ }^{\circ} 09(12 / 12 / 2011)$ versa, ao narrar a $3^{\circ}$ Conferência Nacional de Políticas para as $\mathrm{Mu}-$ lheres que contou com a participação da presidente Dilma. Em relação às medidas criticadas pelas feministas durante o evento, a Folha cita a Rede Cegonha $^{3}$ (RC) cujo foco é a saúde materna. Ela completa que ". . . o enfoque dado à saúde materna em detrimento da 'saúde reproduti$v a$ ' da mulher . . jogaria para baixo do tapete uma discussão sobre a legalização do aborto no Brasil" (Foreque \& Nublat, 2011).

A Rede Feminista de Saúde e a CNBB eram os dois únicos representantes da sociedade civil no lançamento da RC. Aliás, a FPMDV também chegou a apoiar e apresentar a estratégia um dia antes de ser lançada. Para Machado (2012) isso demonstra a mútua relação entre as forças do setor religioso, segmentos e alianças das instituições eclesiásticas com o Estado. Pinto (2013) observa que, tanto na RC como na Medida Provisória 557/2011, ${ }^{4}$ há uma preocupação com o acompanhamento de todas as mulheres gestantes atendidas pelo Sistema Único de Saúde (SUS), o que viabilizaria inibir à interrupção da gravidez. Pode-se pensar que a antiga vigília e pedagogia eclesial dos confessores do Brasil Colonial foram se deslocando até as estratégias em saúde que vão de encontro ao discurso religioso sobre a maternidade, a vida e a família. Especialmente nos eixos da maternidade e da família, a pastoral cristã vem atuando diretamente, pois o cristianismo clássico surge sustentando-se no dispositivo de aliança e nas suas regras próprias, porém na atualidade é ele quem se esforça para sustentar esse antigo dispositivo (Foucault, 1976/1999b).

Criada pela portaria Ministério da Saúde (MS)/ $\mathrm{GM} \mathrm{n}^{\mathrm{o}} 1.459 / 2011$ consiste numa estratégia do MS para o enfrentamento da mortalidade materna, e a melhoria da atenção obstétrica, parto e nascimento.

4 A Medida Provisória 557/2011 revogada pela presidente Dilma, Guido Mantega, Alexandre Padilha e Miriam Belchior em 26/12/2011, vinha subsidiar provisões de acompanhamento da gestante na RC através de um “... . sistema nacional de cadastro, vigilância e acompanhamento da gestante e puérpera para prevenção da mortalidade materna" (Medida Provisória ${ }^{\circ}$ 557, 2011 apud Pinto, 2013, p. 15).
Logo no início de 2012 a presença da "descriminalização do aborto de anencéfalos" já era veiculada como uma das pautas do Supremo Tribunal Federal (STF). Na primeira matéria sobre o assunto ( $\left.\mathrm{n}^{\circ} 13,01 / 01 / 2012\right)$, mais uma vez, a descriminalização do aborto aparece como uma "polêmica".

Convém destacar que, em trechos da Arguição de Descumprimento do Preceito Fundamental (ADPF-54), consta:

Busca-se tão somente que os referidos enunciados [tipos penais] sejam interpretados conforme à Constituição . . . mostra-se inteiramente despropositado veicular que o Supremo examinará . . . a descriminalização do aborto [grifo nosso] . . . existe distinção entre aborto e antecipação terapêutica do parto. (Aurélio, 2012, p. 30)

A despeito da Folha (Agência Brasil de São Paulo, 2012) ter utilizado o termo "descriminalização do aborto" o relator da ADPF-54 foi categórico em relação ao propósito do julgamento. Porém, a palavra aborto já é saturada de significados ideológicos em disputa por grupos com posições contrárias no debate sobre sua legalização e a mídia é um espaço essencial entre esses grupos, com influência nas decisões políticas (Lemos, 2013).

Embora a Folha pareça ter delegado ao aborto de fetos anencefálicos, papel coadjuvante na formação da imagem do STF, o ministro Cezar Peluso, que presidiu a sessão à época, o referiu como "o mais importante da história do Supremo" (Marcello, 2012). Já numa outra matéria veiculada mais próxima à data do tribunal ( $\mathrm{n}^{\circ} 26$ de 10/04/2012), o ministro Ayres Britto afirmava: "o país tinha um encontro marcado com esse tema. Ele é divisor de águas no plano da opinião pública, repercute muito no campo da religiosidade, da saúde pública. Um tema grandioso pelo seu impacto ....".

A fala de Britto refere-se à chegada do tema à corte desde o ano de 2004 e atribui à antecipação do parto nos casos de anencefalia ressonância nas esferas da religião e da saúde pública, sob a ótica de uma concepção de "vida" modificável. Nesse sentido, no ano de 2012, os domínios da religiosidade e da Saúde Pública é que parecem 
ditar a tônica dos discursos nacionais sobre a legalização do aborto.

Retomando a legalização do aborto ao posto de "polêmica", a Folha (Agência Brasil de São Paulo, 2012) declara: "a polêmica parece longe de terminar". O trecho sugere a estreita dependência entre a permanência da referida "polêmica" e essa entidade cujos lobbys religiosos tiveram participação restringida no processo de julgamento (Aurélio, 2012). Forçoso pensar que, a Folha principia-se num discurso de neutralidade, não reconhecendo seu papel na manutenção, classificação e interpretação do tema sobre o viés de "polêmica". Entretanto, Pinho (2009) reforça a ideia de que além de determinar o assunto do debate, a mídia também determina quais são as interpretações válidas na discussão de um tema.

Em relação ao âmbito da Saúde Pública, houve disputa pelo sentido conotativo da palavra "aborto". Lemos (2013) relembra que, num diálogo, as palavras não são neutras, existindo uma batalha pelo seu sentido, não apenas como pecado, mas também como questão de saúde ou de direitos. Isso pode ser observado na matéria $\mathrm{n}^{\circ} 15(07 / 02 / 2012)$, no discurso de Eleonora Menicucci, nova ministra da Secretaria de Políticas para as Mulheres (SPM): "O aborto . . é uma questão de saúde pública, não é uma questão ideológica [grifos nossos]. Como o crack, as drogas, a dengue, o HIV, todas as doenças infecto-contagiosas".

Essa consignação da ministra Menicucci foi reprovada pelos setores religiosos empenhados na criminalização do aborto. Conforme o discurso do deputado Eduardo Cunha (PMDB) na matéria $n^{\circ} 16(09 / 02 / 2012)$, a imagem da ministra é associada ao pecado:

... Menicucci está no lugar e na época errados . . . ela deveria estar em Sodoma e Gomorra . . essa posse da abortista amanhã é sintomática para todos nós e devemos mostrar de forma contundente a nossa revolta. ABORTO NAO! (sic).

O discurso da ministra da SPM também foi repudiado na Câmara dos Deputados pelos parlamentares Eros Biondini (PTB-MG), Manato (PDS-ES) e Pastor Eurico (PSC-PE) a partir do prisma religioso (Congresso Nacional, 2012).
Nessa mesma data $(16 / 02 / 2012)$, na matéria $n^{\circ}$ 19 (16/02/2012), em seu discurso, o secretário-geral da CNBB Dom Leonardo Steiner afirma:

[O posicionamento de Menicucci] incomodou muito gente, não só a CNBB. Mas faço distinção, ela fez um pronunciamento pessoal, depois disse que não era a posição do governo. Gostaríamos de reafirmar que a questão do aborto não pode ser entendida como questão ideológica [grifo nosso]. Nós colocamos como o sentido de vida humana. No discurso da ministra, a legalização do aborto aparece sobre a prerrogativa de que "nenhuma pessoa de gestão que tenha sensibilidade e ouça os números admite que as mulheres continuem morrendo em decorrência de aborto". Apesar de não citar os números, ela tentou embasar seu discurso empiricamente, para conferir materialidade e realidade ao aborto como problema de Saúde Pública, numa concepção de ideologia análoga à compreensão marxista na qual a ideologia consiste num sistema de ideias e valores ilusórios que mascaram a realidade social (Brandão, 2004). Já o discurso de Steiner, como de praxe nas esferas cristãs, pode abarcar outro sentido de ideologia, da qual o sentido de vida não faz parte, mesmo porque a vida representa para os blocos cristãos contrários ao aborto, um princípio transcendente (Almeida \& Bandeiras, 2013).

Conforme discurso do arcebispo de Sorocaba Dom Eduardo Benes, no site da CNBB (Rodrigues, 2012) há concordância parcial com o discurso de Menicucci:

Estou de acordo [não ser questão ideológica], mas com conclusões opostas . . o poder público deveria combater . . com rigor os donos de clínicas clandestinas e oferecendo acompanhamento médico para todas as grávidas para que não sejam vítimas da violência do abortamento. Por não ser uma questão ideológica, mas uma questão ética, é dever de todos, sobretudo dos governantes, empregarem todos os meios [grifo nosso] para banir da sociedade tão hedionda prática.

O discurso do arcebispo aceita que todos os meios sejam empregados na extinção da prática 
do aborto, o que reforça a sensibilidade das instituições religiosas à temática. Ainda sobre o pronunciamento da ministra da SPM, o padre Marcelo Rossi disse na matéria ${ }^{\circ} 20$ (27/02/2012): "Existem princípios que regem a igreja e, se forem violados, há mobilização. Se um candidato for a favor do aborto, não só eu, mas também setores evangélicos, vão se mobilizar contra". Esse discurso parece considerar que os princípios da Igreja estão acima dos preceitos constitucionais, pois entende que a posição favorável à legalização do aborto é que viola a religião, desconsiderando o caráter laico Estado no Brasil.

Decerto, a oposição entre o discurso da ministra e dos religiosos traz a tona uma típica polaridade entre os grupos denominados "pró-vida" e "pró-escolha". Originalmente derivados do caso norte-americano em 1973, no qual a jovem Jane Roe lutou pelo direito ao abortamento no Texas (Borsari et al., 2012), essas categorias, surgiram no cenário brasileiro por volta das décadas de 1970 e 1980 em meio ao debate iniciado pelo movimento feminista sobre a legalização do aborto (Hentz, 2013). As principais divergências referem-se aos direitos das mulheres e da vida nascitura, ao início da vida, a legitimidade e a constitucionalidade da prática do aborto. Porém, tanto os argumentos "pró-escolha" como os "pró-vida" podem ser baseados nos mesmos dispositivos jurídicos e campos de saber. Isso ocorre porque não são necessariamente, as distintas áreas do saber ou as devidas legislações, responsáveis pelas óticas diferentes sobre o abortamento, mas, eventualmente, a moralidade de cada grupo procura conciliar discursos jurídicos, médicos e religiosos ao ponto de vista que defende (Valpassos, 2011).

Assim como as eleições presidenciais de 2010, as eleições municipais de 2012 contaram com a veiculação de panfletos recomendando não votar em candidatos "pró-aborto". Conforme o discurso (nº 23 de 21/03/2012) do bispo de Guarulhos, Dom Luiz Bergonzini: “. . . Provamos que o PT e Dilma Rousseff eram e continuam sendo a favor da liberação do aborto". Para os religiosos essa prova residia na contratação da ministra Eleonora Menicucci.
Desse modo o ano de 2012 foi marcado pela disputa, sobretudo, pelo sentido da palavra aborto. O possível deslocamento do tema para o campo da Saúde Pública apareceu na visão dos setores contrários, como provável ameaça de legalizar o aborto, pressionando Menicucci na redução do seu discurso a "opinião pessoal" ( ${ }^{\circ} 15$ de 07/02/2012) reiterando a posição do governo, nesse caso o compromisso da presidenta Dilma para com os religiosos: "Minha posição pessoal [grifo nosso] está em todos os jornais . . . Mas sou governo, minha posição hoje é de governo".

Desde outubro de 2011, iniciava-se um processo de Revisão do CP que, a partir de então teve anteprojeto elaborado em março de 2012 por uma Comissão de juristas instituída pelo Senado (Senado Federal, 2013). Devido ao teor das propostas contidas, ${ }^{5}$ o texto do anteprojeto do CP (PLS 236/2012) parece ter sedimentado a polarização entre os grupos favoráveis e os grupos contrários a legalização do abortamento. Através da Circular N 46/2013 do Conselho Federal de Medicina (CFM), Roberto d'Avila, após o I Encontro Nacional de Conselhos de Medicina (ENCM) de 2013, em Belém, proclamou a posição oficial da maioria dos Conselhos favorável à autonomia das mulheres e à ampliação dos excludentes de ilicitudes penais nos casos de aborto (CFM, 2013a).

O Conselho Federal de Psicologia (CFP) também já havia se posicionado favoravelmente à legalização do aborto desde a chegada do anteprojeto de reforma do CP à comissão de juristas organizada pelo Senado e apoiado a decisão do CFM, reconhecendo seu avanço, sobretudo, em razão de sua posição assentar-se primordialmente na vontade da mulher (CFP, 2013; Pires, 2013). Por outro lado, tal dimensão é desprezada no posicionamento do presidente do CRM-MG, João Batista Soares: “. . . Existem situações espe-

\footnotetext{
Não só a liberação do aborto até a $12^{\circ}$ semana de gestão nas hipóteses de emprego não consentido de técnica de reprodução assistida ou vontade da gestante na constatação médica ou psicológica de incapacidade de arcar com a maternidade, como também, a eutanásia; a criminalização da homofobia.
} 
ciais que justificam [o aborto]. Agora, simplesmente porque a mulher não quer ter aquele filho, ai somos contra" (Matéria $\mathrm{n}^{\circ}$ 41, 23/03/2013).

$\mathrm{Na} \mathrm{n}^{\circ} 38$ (21/03/2013), o bispo da CNBB, Carlos Petrini, moralizou o pronunciamento do CFM:

O que consideramos grave nesse contexto é o poder educativo - que é deseducativo, na verdade - . . o Conselho Federal de Medicina tem, o poder de criar mentalidades... Do contrário, se fortalece uma mentalidade que favorece o recurso à violência e à morte ... num contexto em que o Brasil está assolado por indices de violência que nos colocam em situação parecida com países que estão em guerra.

A fala do bispo parece atribuir caráter antipedagógico ao posicionamento do CFM, porém como o que é dito não é dito de qualquer lugar (Foucault, 1969/2008), ele não fala em nome de uma educação qualquer, e sim de uma educação cristã, pois a Igreja se opõe ao uso dos métodos contraceptivos, sendo, sobretudo, resistente a educação sexual nas escolas. Na Semana Nacional da Família (SNP), a página virtual da CNBB (2013) continha um texto que apresentava os principais desafios na educação cristã:

[um dos desafios] está na maneira de conceber o ser humano, ameaçado pela ditadura do relativismo ... As consequências de não correspondência ao desígnio de Deus são desastrosas para a pessoa, família e sociedade. Assim se explica a justificação do aborto como um direito da mulher [grifo nosso], as tentativas de legalizar a eutanásia, o controle artificial dos nascimentos, as leis cada vez mais permissivas do divórcio, as relações extraconjugais, as uniões homoafetivas e outras.

No discurso acima o apoio à legalização do aborto rompe com o "desígnio de Deus" - a quem pertence o poder sobre a vida e a morte. $\mathrm{Na}$ verdade, o aborto era considerado um pecado e, não um homicídio. Bursztyn et al. (2009) relembram que a radicalização da posição da Igreja Católica data de 1995 - ocasião na qual o Papa João Paulo II admoestou a sociedade moderna sobre o surgimento de uma "cultura da morte", indicando que o aborto não poderia ser legalizado. Já a associação do aborto à violência no discurso de Petrini, traz uma concepção que não engloba a violência institucional sofrida pelas mulheres (a maioria, católicas e religiosas) praticada por profissionais de saúde que se orientam a partir de suas crenças e tentam impor-lhes as mesmas (Soares et al., 2011).

Historicamente a medicina teve sua imagem associada à religiosidade e à Igreja. Foucault (1961/1978, 1979/2001) relembra que a medicina esteve ligada às instituições religiosas, sendo que os primeiros Hospitais Gerais derivavam de estabelecimentos monásticos e, só então, vinculando-se ao Estado pôde estabelecer uma "arte da cura" ou mesmo, ser compreendida como estratégia biopolítica. Assim, pode-se pensar numa imagem social do médico como salvador de vidas, de modo que, onde se entende o aborto como "homicídio", a medicina passa a ser vista a serviço da morte.

Assim, na atualidade a vida é elencada como paradigma (Hentz, 2013), mas ao se deparar com a realidade empírica do abortamento, as corporações de referência em medicina são compelidas a se posicionarem. É claro que, parte da medicina também procura se afastar de uma imagem higienista e moralista, do "positivismo militante", na expressão de Castelbajac (2010). Deve-se considerar ainda, que no início do século XX, a medicina incipiente no Brasil, auxiliou na anexação da mulher à maternidade como destino. Esse movimento faz parte, especialmente, de uma tecnologia do sexo formada no final do século XVIII, que não era totalmente independente dos temas religiosos, mas escapava às instituições eclesiásticas, de modo que a prática médica alinhava-se aos interesses demográficos, combatendo, essencialmente, as referidas "fraudes contra a procriação" e "contra a natureza" (Foucault, 1976/1999b).

Esse posicionamento, entretanto, parece causar estranheza, conforme a fala de um dos leitores (n 41) da Folha ("Evangélicos fazem protesto", 2013):

Se os médicos se colocam contra a vida, isso é sinal de uma séria subversão de valores que felizmente, não parece ter contami- 
nado ainda o povo brasileiro . . . Ninguém como os médicos tem mais obrigação de saber que, depois da fecundação, é de um ser humano que estamos falando...

O discurso do leitor parece tentar reajustar a imagem da medicina à posição com a qual ela rompeu, pois a sociedade ainda tem dificuldade de assimilar as justificativas para o aborto legal, sobretudo, por parte dos médicos (Carvalho, Gonçalves, \& Carvalho, 2013). Ambiguamente, o leitor concebe certa autoridade aos médicos para dissertar sobre a vida, mas acaba se colocando acima deles ao querer lembrar-lhes sobre a origem da vida humana.

Segundo a matéria $n^{\circ} 42(26 / 03 / 2013)$, os líderes das bancadas religiosas do Congresso Nacional solicitavam esclarecimento por parte de d' Avila:

Queremos que ele venha à comissão para um debate, colocando as razões porque chegou a essa decisão . . . E com quem se reuniu para tomar essa decisão . . . Aos três meses, você vai tirar um feto aos pedaços para jogar no lixo ... É um assassinato que existe em massa no Brasil. . . . Temos que criminalizar quem comete crime consciente. Essa proposta é infame porque está chamando para legalizar o crime. $\left(\mathrm{n}^{\mathrm{o}} 42\right.$, 26/03/2013, grifos nossos)

$\mathrm{Na}$ verdade, cerca de seis dias antes (21/03/2013) o portal do CFM (2013b) já havia divulgado uma nota esclarecendo seu aval à legalização do aborto. Na nota também é mencionada a discussão do CFM com os 27 conselhos regionais de medicina há dois anos. Desse modo, o discurso do Senador evangélico Magno Malta (PR-ES) esboça uma flexibilidade e disposição parcial ao debate que reivindicara, já que sua visão traz o crime como "natural". Para ele é preciso "criminalizar" mesmo o que já é "crime", como se o crime sempre existisse antecedendo a criminalização que assim o denomina.

Que se pese o fato ainda, de que Malta articulava as bancadas religiosas tanto no sentido de vedar o anteprojeto de reforma do $\mathrm{CP}$, como organizar protestos nos próximos dois meses ("Evangélicos fazem protesto", 2013). Para Barreras e Weber (2014) o ativismo religioso, con- ta com lideranças bem delimitadas, ocupando o ambiente público pontualmente na manutenção de seus valores e defesa de suas bandeiras. Nessa ocasião, o Estatuto do Nascituro havia sido aprovado pela Câmara dos Deputados. Mas, no mesmo mês outros movimentos compostos pela Liga Brasileira de Lésbicas, a Marcha das Vadias e a Marcha Mundial das Mulheres também organizaram manifestações empenhadas na legalização do aborto.

A marcha das Vadias se inseria num contexto oportuno, já que, em Agosto de 2013, a presidenta Dilma sancionara a Lei $\mathrm{N}^{\circ} 12.845$ que dispõe sobre o atendimento obrigatório e integral de pessoas em situação de violência sexual (Lei $\mathrm{N}^{\circ}$ 12.845, 2013). Dentre os serviços abrangidos, a "profilaxia da gravidez" que oferece a pílula de emergência e informações sobre o direito ao aborto à vítima de estupro, repercutiu na Câmara dos Deputados entre os deputados evangélicos.

Desconfiava-se da preparação "do cenário político e jurídico para a completa legalização do aborto no Brasil" (Pastor Eurico - PSB-PE; Matéria $\left.{ }^{0} 51,09 / 08 / 2013\right)$. Dessa forma, de um lado estava o Estatuto do Nascituro e, de outro, a lei $\mathrm{N}^{\circ} 12.845$ e o anteprojeto o qual a Folha $\left(\mathrm{n}^{\circ}\right.$ 40 de 22/03/2013) já anunciava não ter tido uma recepção forte, mesmo com o respaldo do CFM. Nessa matéria a Folha relembrou à posição de Pedro Taques - "favorável a vida" - que na versão final do texto do anteprojeto não diferiu. $\mathrm{Na}$ íntegra, Taques teria dito se basear na inconstitucionalidade do artigo que predizia o aborto segundo o desejo da gestante, mas na página de Magno Malta consta que "Pedro Taques acatou os argumentos religiosos" (Malta, 2013). Ele diz o seguinte: "Em relação ao aborto, o relatório aprovado, do senador Pedro Taques, já atendeu à Frente de Família. No entanto, enquanto o texto não for aprovado em plenário, alguém pode destacar e mudar tudo. É por isso que estamos vigilantes".

Desde o ano de 2013, a presidenta Dilma demarcava um posicionamento ambivalente em relação às demandas dos religiosos e dos movimentos de mulheres. Para a Folha $\left(\mathrm{n}^{\circ} 45\right.$ de 15/04/2013), Dilma e o Planalto "fogem" dos temas "polêmicos": 
Dilma já se posicionou a favor da descriminalização do aborto, mas mudou de ideia na campanha eleitoral. O Palácio do Planalto espera que... [o tema não seja central] na disputa por 2014, o que diminuiria o peso das demandas evangélicas na corrida eleitoral.

Devido ao ano de eleições presidenciais, o tema da legalização do aborto teve aparição reduzida, com exceção da matéria ${ }^{\circ} 57$ (22/06/2014), na qual Luciana Genro (PSOL) inseria a pauta em seu programa:

Ela pretende levar para o debate eleitoral temas considerados polêmicos e, por isso, evitados pelos principais candidatos à Presidência. Luciana irá defender a descriminalização da maconha, a garantia dos direitos $L G B T$ e a legalização do aborto como política pública de saúde.

Cientes do repúdio de parte da sociedade e dos setores religiosos, os "principais candidatos" parecem ter evitado o assunto. Por não permitir o posicionamento imediato sem que isso afete a campanha dividindo o eleitorado, o marketing eleitoral considera a legalização do aborto um tabu (Barreras \& Weber, 2014).

Em entrevista à Folha, em maio de 2014 ("Leia a transcrição da entrevista de Aécio Neves"), o candidato à presidência Aécio Neves (PSDB), afirmara laconicamente: "[ser a favor das] regras atuais [sobre o aborto]". Já em outra entrevista da Folha (Rodrigues, 2014), o candidato à presidência pelo PV, Eduardo Jorge, criticava a posição dos adversários sobre o aborto:

. . usando [Dilma, Aécio e Campos] uma linguagem bíblica, estão entrando como Pilatos na história. Estão lavando as mãos, porque não é essa a posição pessoal deles. Eles sabem muito bem do drama das mulheres... É isso [estão mentindo]. Ou mentem ou se omitem. Não sei o que é pior.

No discurso supradito, Jorge compara o posicionamento dos presidenciáveis ao personagem bíblico Pôncio Pilatos ${ }^{6}$ e, parece sugerir

Em Mateus 27:17 “... Qual quereis que vos solte? Barrabás ou Jesus, chamado Cristo? . . E eles disseram: Barrabás. Disse-lhes Pilatos: Que farei que a posição dos candidatos mantenha a harmonia com os setores conservadores, tal como nas eleições de 2010 (Fontes, 2012). Com a maior difusão, visibilidade e hegemonia das religiosidades cristãs nos meios de comunicação, em detrimento de outras, juntamente com o silenciamento do governo e falta de deliberações do executivo e legislativo, Barreras e Weber (2014) vislumbram a neutralização do debate público, necessário à veiculação de argumentos e opiniões de organizações pouco visíveis como a Católicos Pelo Direito de Decidir, o Centro Brasileiro de Estudos sobre Saúde (CEBES) e o Grupo de Estudos Sobre o Aborto (GEA).

\section{Discurso Religioso}

Não obstante as suas formas de vinculação com a política, os discursos da religião católica e evangélica são os de maior hegemonia no corpus analisado. A legalização do aborto aparece no discurso religioso como uma medida "infame" que dispõem de emprego da morte e da violência. Essa conotação imputada à legalização do aborto tem possível vínculo com a concepção religiosa dos grupos "pró-vida" na qual o sentido da vida transcende o caráter ideológico e se articula com o designío divino.

Desta forma, o discurso religioso se inscreve como detentor da verdade absoluta e por isso mesmo, possuidor da patente da ética e da moral. Apesar do autoritarismo que esse discurso implica, ele não se reconhece como tal, pois se faz esquecer-se do próprio ato de sua origem (Foucault, 1970/1999a). Esse discurso também parece negar e retroagir a um passado no qual representantes notáveis da Igreja foram complacentes com a prática do abortamento.

Como titulares da verdade absoluta, para Foucault (1970/1999a, p. 22) os discursos religiosos, “. . . indefinidamente e para além da sua formulação, são ditos, ficam ditos, e estão ainda por dizer". Essa característica cria um tom profético ao discurso, segundo o qual a legalização do aborto "deseducaria", pois foge ao uso legítimo

então com Jesus, chamado Cristo? Disseram-lhe todos: Seja crucificado" (Bíblia Sagrada, n.d., pp. 21-22). 
do sexo - procriação - e estimularia as mulheres ao pecado sobre um ser indefeso e fruto do desígnio divino, degradando o valor da vida e da família.

\section{Discurso Sanitário}

O uso das técnicas de estatísticas tem por consequência a produção de uma norma (Foucault, 1976/1999b, 1969/2008) sobre a frequência do aborto, da morbidade e mortalidade por essa prática, diante da qual, cada discurso propõe um procedimento a ser realizado a partir de determinadas premissas. Analisando o corpus de matérias, observou-se a existência de, pelo menos, dois tipos de discursos sanitários: o discurso da redução de danos e o discurso higienista, ambos proferidos, principalmente, por acadêmicos e profissionais da saúde.

A representatividade dos "números" mostraria à ineficiência da norma jurídica sobre o aborto que, não evita os prejuízos à saúde e a vida da gestante e nem ao feto. Assim, a legalização do aborto aparece como medida capaz de reduzir os danos oriundos da criminalização da prática, os quais incidem também na autonomia reprodutiva das mulheres sobre o próprio corpo.

Já o discurso higienista, pode ser assim denominado porque propõe o endurecimento da lei ou aplicação mais rígida, como se quisesse purificar o espaço social, eliminando dele aquilo que lhe causa insalubridade (Castelbajac, 2010). Causa insalubridade porque perpetua a irresponsabilidade na medida em que liberar o aborto seria um "atestado de irresponsabilidade" de acordo com Taques (2013) e legalizá-lo provocaria desordem. Assim, essa prática não possui causalidade derivada da norma atual, em seu sentido amplo - coexistente com a variedade de métodos contraceptivos - mas da irresponsabilidade, inaptidão e negação da maternidade.

Parece existir uma minimização e esvaziamento dos aspectos psicológicos e subjetivos, como o desejo e a autonomia. Provavelmente por reduzir esses elementos, é que esse discurso cria condições para negar a possibilidade de que eles justifiquem a ampliação das hipóteses de aborto. Além disso, o uso da palavra "filho" para se referir ao embrião ou ao feto, sugere a concep- ção da feminilidade direcionada à maternidade, já que antecipa o respectivo papel que não pode ser sobreposto pelo mero desejo cujo potencial na causação de sofrimento psíquico é subestimado. Pela desqualificação da subjetividade esse argumento pode ser calçado, uma vez que ela tem peso nas hipóteses de estupro e anencefalia (Aurélio, 2012).

\section{Discurso Feminista}

O discurso feminista também se mostra presente no corpus analisado. Nele, a legalização do abortamento aparece como uma maneira de ampliar os direitos sobre o próprio corpo e a reprodução. Assim a legalização do aborto possibilitaria a ruptura com as normas sociais resultantes de uma dominação histórico-social do gênero masculino sobre o feminino, sobretudo, aquelas que repreendem ou fixam as mulheres ao papel materno através de políticas públicas com enfoque materno-infantil.

Nesse discurso, que desde a década de 1970 tem ganhado a aderência dos movimentos de mulheres e, mais recentemente da Marcha das Vadias, há uma crítica declarada ao machismo que dificulta a maior participação política das mulheres, do qual a lei do aborto é considerada reflexo.

\section{Discurso Midiático}

Numa grande quantidade de matérias analisadas, a legalização do abortamento aparece no discurso da Folha como um tema "polêmico" e "espinhoso". Assim, a legalização do aborto surge nos discursos reproduzidos pela Folha como objeto de disputa e controvérsia entre atores, grupos e instituições contrárias, de modo que o debate tende a aparecer de forma polarizada. Frisa-se a reprodução de discursos que entram em colisão com outros discursos, como o discurso feminista, eleitoreiro e religioso, ou entre os discursos sanitários. Parece ser a partir dessa cena narrativa que a Folha constrói, então, o título de "polêmica".

No que tange a polaridade em torno de grupos mais próximos às ideias "pró-escolha" e outros, às ideias "pró-vida", ela pode criar dificuldades. Uma dessas dificuldades, conforme 
adverte Sagan (1998), é a distribuição automática de argumentos e discursos num dos lados do debate, impedindo que se vejam formas consensuais (Barreras \& Weber, 2014). Pires (2013) relembra que revisão do $\mathrm{CP}$ em relação ao aborto não era, por exemplo, uma liberação radical dessa prática, e sim, uma norma cujo prazo estabelecido para interrupção da gravidez até as $12^{\circ}$ semanas de gestação, pautava-se na presença de riscos maiores envolvendo o aborto nos períodos mais avançados e a formação do sistema nervoso central (CFM, 2013a). Oficialmente, a Folha de São Paulo ("Aborto: O que a Folha pensa", 2014) se declara contrária à criminalização do abortamento, mas avisa aos leitores que independentemente de concordarem ou não, ela publica opiniões distintas. Nesse sentido, ela deve dar mostras da publicação de outros posicionamentos, porém ao fazê-lo, a conotação como polêmica passa a derivar exclusivamente do choque entre os discursos contrários que são veiculados, sem que a interferência da Folha tenha visibilidade, o que cria a impressão de seu discurso ser neutro. Entretanto, Barreras e Weber (2014) constatam que a mídia tem o poder de autenticar, sobretudo, as pautas produzidas na imprensa, o que permite contestar essa impressão.

\section{Discurso Eleitoreiro}

Frente à possiblidade de divisão do eleitorado através do delineamento da posição sobre a legalização do aborto, esse tema, no período analisado, foi tratado de modo comedido por candidatos políticos. Buscando a aceitação dos setores conservadores e dos setores progressistas, há um discurso eleitoreiro que visa à obtenção e manutenção de votos, o que repercute em posicionamentos ambíguos.

Esse discurso é criticado pelos religiosos, feministas e outros candidatos, pois em temas como a legalização do aborto, a tentativa de acolher as demandas de uma parte do eleitorado, implica na renúncia das demandas de outra parte, acarretando em ambivalência e na ampliação da demanda pela laicidade de Estado (Machado, 2012).

\section{Considerações Finais}

A prática do aborto esteve presente na história desde as civilizações mais remotas, passando de um assunto privado a um objeto de disputas entre grupos distintos. Em sua forma extrema, essa disputa assume a fórmula de uma polaridade entre grupos "pró-vida" e "pró-escolha" cujos discursos têm visibilidade na mídia. A mídia (re) produz discursos sobre esse assunto que são veiculados nas matérias, sendo que sua expressão pode ter relação com as nuances de cada período.

O ano de 2011 sucedia a campanha eleitoral e o tema enfrentou tentativas de silenciamento por parte dos setores religiosos. Já o período de 2012 foi marcado pela decisão do STF em favor da liberalização do aborto nos casos de anencefalia, contribuindo para o deslocamento do tema para a esfera da saúde pública que foi fortalecido em 2013 com a posição inédita do CFM para respaldar o anteprojeto de reforma do $\mathrm{CP}$ que acirrou o embate com os grupos opostos à legalização do aborto, de modo que o primeiro semestre de 2014 contou com a esquiva do tema por parte dos presidenciáveis.

Os principais discursos veiculados foram: o discurso religioso, que associa a legalização do aborto a uma proposta torpe, violenta e assassina da vida de um ser inocente; discurso sanitário da redução de danos que através da legalização do aborto visa minimizar os impactos da criminalização dessa prática; discurso sanitário higienista que procura manter a criminalização das mulheres para não disseminar a irresponsabilidade que circunda o aborto; discurso feminista, que vê na legalização do aborto a possibilidade de rompimento com consequências deixadas pelo machismo; discurso eleitoreiro no qual a legalização do aborto é objeto de negociação de votos e de alianças com grupos distintos da sociedade. Enfim, o discurso da própria mídia que, se propõem à neutralidade, mas parece ter papel na construção do tema sob a designação de "polêmica" e de um embate entre setores antagônicos.

Embora a mídia apresente o debate ao público geral, os discursos (re)produzidos pela $\mathrm{Fo}^{-}$ 
lha de São Paulo apontam para perspectivas que veiculam o assunto enquanto polêmica ou tabu, o que implica na necessidade de reflexão sobre esse veículo, sobre sua interferência provável na legitimação de uma prática social que tem aceitação quando ocorre de forma silenciosa e invisível, nos modos hegemônicos de agir e pensar; na definição da agenda em saúde pública.

\section{Referências}

Aborto: O que a Folha pensa. (2014, $1^{\circ}$ ago.). Folha de São Paulo. Recuperado em http:// www1.folha.uol.com.br/multimidia/tvfolha/ 2014/08/1493937-aborto-o-que-a-folha-pensa. shtml

Agência Brasil de São Paulo. (2012, 10 abr.). Julgamento sobre aborto de anencéfalos será divisor de águas, diz ministro. Folha de São Paulo. Recuperado em http://wwwl.folha.uol.com.br/ cotidiano/1073919-julgamento-sobre-abortode-anencefalos-sera-divisor-de-aguas-diz-ministro.shtml

Almeida, T. M. C., \& Bandeira, L. M. (2013). O aborto e o uso do corpo feminino na política: A campanha presidencial brasileira em 2010 e seus desdobramentos atuais. Cadernos Pagu, 18(41), 371-403. doi:10.1590/S010483332013000200018

Aurélio, M. (2012). Arguição de descumprimento de Preceito Fundamental 54. Supremo Tribunal Federal.

Barreras, S. B., \& Weber, M. H. (2014). A neutralização do debate sobre o aborto o ativismo político-religioso e o silenciamento do governo. Compós, 1-21. Recuperado em www.compos. org.br/encontro2014/anais/...E_POLITICA/ compos_2176.pdf

Borsari, C. M. G., Nomura, R. M. Y., Benute, G. G., Nonnenmacher, D., Lucia, M. C. S., \& Francisco, R. P. V. (2012). O aborto inseguro é um problema de saúde pública. FEMINA, 40(2), 63-68. Recuperado em http://files.bvs.br/ upload/S/0100-7254/2012/v40n2/a3094.pdf

Brandão, H. H. N. (2004). Introdução à análise do discurso (2. ed.). Campinas, SP: Editora da Universidade Estadual de Campinas.

Brandão, H. H. N. (2009). Analisando o discurso. Museu da Língua Portuguesa, 1-28.
Bursztyn, I., Tura, L. F. R., \& Correa, J. S. (2009). Acesso ao aborto seguro: Um fator para a promoção da equidade em saúde. Physis: Revista de Saúde Coletiva, 19(2), 475-487. doi:10.1590/ S0103-73312009000200013

Carvalho, J., Gonçalves, D. W. P. O., \& Carvalho, H. (2013). A legalização do aborto em casos de anencefalia no Brasil. RIDB: Revista do Instituto do Direito Brasileiro, 2(4), 2791-2830. Recuperado em http://www.idb-fdul.com/uploaded/ files/2013_04_02791_02830.pdf

Castelbajac, M. (2010). Aborto legal: Elementos sociohistóricos para o estudo do aborto previsto por lei no Brasil. Revista de Direito Sanitário, 10(3), 39-72. doi:10.11606/issn.2316-9044. v10i3p39-72

Conferência Nacional dos Bispos do Brasil. (2011). Moção de apoio à Frente Parlamentar Mista em Defesa da Vida-Contra o Aborto. Recuperado em http://www.cnbb.org.br/ index.php?option $=$ com_docman\&view $=$ document\&alias =1398-mocao-de-apoioa-frente-parlamentar-mista-em-defesada-vida-contra-o-aborto\&category slug $=$ documentos $\&$ Itemid $=252$

Conferência Nacional dos Bispos do Brasil. (2013, ago.). Vida e Família: Semana Nacional da Família: Desafios na educação cristã/católica dos filhos. Recuperado em http://www.cnbb. org.br/index.php?option=com_content\&view $=$ article $\&$ id $=12617$ :semana-nacional-da-familia-desafios-na-educacao-cristacatolica-dos-filhos\&catid $=196 \&$ Itemid $=179$

Congresso Nacional, Câmara dos Deputados. (2011, 8 abr.). Ata da $61^{\text {a }}$ sessão da câmara dos deputados, extraordinária, matutina, da $1^{\mathrm{a}}$ sessão legislativa ordinária, da $54^{\mathrm{a}}$ legislatura, em 7 de abril de 2011. Diário da Câmara dos Deputados, 66(57). Recuperado em imagem.camara.gov.br/ Imagem/d/pdf/DCD08ABR2011.pdf

Congresso Nacional, Câmara dos Deputados. (2012, 16 fev.). Ata da $12^{\mathrm{a}}$ sessão da câmara dos deputados, extraordinária, matutina, da $2^{\mathrm{a}}$ sessão legislativa ordinária, da $54^{\mathrm{a}}$ legislatura, em 15 de fevereiro de 2012. Diário da Câmara dos Deputados, 67(18). Recuperado em imagem.camara. gov.br/Imagem/d/pdf/DCD16FEV2012.PDF

Conselho Federal de Medicina. (2013a). Circular $C F M N^{\circ}$ 46/202013. Brasília, DF: Autor. Recuperado em https://waldircardoso.files.wordpress. com/2013/03/ofc3adcio-circular-cfm-46-2013. pdf 
Conselho Federal de Medicina. (2013b, 21 mar.). CFM esclarece posição a favor da autonomia da mulher no caso de interrupção da gestação. Recuperado em http://portal.cfm.org.br/index. php?option $=$ com_content $\&$ view $=$ article $\&$ id $=$ 23663:cfm-esclarece-posicao-a-favor-da-autonomia-da-mulher-no-caso-de-interrupcao-da-gestacao\&catid $=3$

Conselho Federal de Psicologia. (2013). Notícias: Aborto. Recuperado em http://site.cfp.org.br/ posicionamento/

Diniz, D., \& Castro, R. (2011). O comércio de medicamentos de gênero na mídia impressa brasileira: Misoprostol e mulheres. Cadernos de Saúde Pública, 27(1), 94-102. doi:10.1590/ S0102-311X2011000100010

Diniz, D., \& Medeiros, M. (2010). Aborto no Brasil: Uma pesquisa domiciliar com técnica de urna. Ciência \& Saúde Coletiva, 15(1), 959-956. doi:10.1590/S1413-81232010000700002

Evangélicos fazem protesto contra o aborto e o casamento gay no DF. (2013, 5 jun.). Folha de São Paulo. Recuperado em http://www1.folha.uol. com.br/cotidiano/2013/06/1290466-evangelicos-fazem-protesto-contra-o-aborto-e-o-casamento-gay-no-df.shtml

Fontes, M. L. A. (2012). O enquadramento do aborto na mídia impressa brasileira nas eleições 2010: A exclusão da saúde pública do debate. Ciência \& Saúde Coletiva, 17(7) 1808-1812. doi:10.1590/ S1413-81232012000700019

Foreque, F., \& Nublat, J. (2011, 12 dez.). Falha de organização gera saia justa para Dilma em evento. Folha de São Paulo. Recuperado em http:// www1.folha.uol.com.br/poder/1020395-falhade-organizacao-gera-saia-justa-para-dilma-emevento.shtml

Foucault, M. (1978). História da Loucura na Idade Clássica (6. ed.). São Paulo, SP: Perspectiva. (Original publicado em 1961)

Foucault, M. (1999a). A ordem do discurso (2. ed.). São Paulo, SP: Edições Loyola. (Original publicado em 1970)

Foucault, M. (1999b). História da sexualidade: A vontade de saber (13. ed.). Rio de Janeiro, RJ: Graal. (Original publicado em 1976)

Foucault, M. (2001). Microfísica do poder (16. ed.). Rio de Janeiro, RJ: Graal. (Original publicado em 1979)
Foucault, M. (2008). A arqueologia do saber (7. ed., L. F. B. Neves, Trad.). Rio de Janeiro, RJ: Forense Universitária. (Original publicado em 1969)

Gregolin, M. R. (2008). Análise do discurso e mídia: A (re)produção de identidades. Сотиnicação, Mídia e Consumo, 4(11), 11-25. doi:10.18568/1983-7070.41111-25

Hentz, I. C. (2013). A honra e a vida: Debates jurídicos sobre aborto e infanticídio nas primeiras décadas do Brasil republicano (1890-1940) (Dissertação de mestrado, Universidade Federal de Santa Catarina, Florianópolis, SC, Brasil).

Lei $\mathrm{N}^{\circ}$ 12.845, de 1 de Agosto de 2013. (2013, 2 ago.). Dispõe sobre o atendimento obrigatório e integral de pessoas em situação de violência sexual. Diário Oficial da União. Recuperado em http://www.planalto.gov.br/ccivil_03/_ato20112014/2013/lei/112845.htm

Leia a transcrição da entrevista de Aécio Neves à Folha e ao UOL - Parte 1. (2014, 22 maio). Poder e Política. Folha de São Paulo. Recuperado em http://www1.folha.uol.com.br/poder/ poderepolitica/2014/05/1458120-leia-a-transcricao-da-entrevista-de-aecio-neves-a-folha-e-ao-uol---parte-1.shtml

Lemos, L. C. (2013, 16-20 set.). Aborto na mídia: Uma análise de ideologia. Anais eletrônicos: Seminário Internacional Fazendo Gênero, 10.

Machado, M. D. C. (2012). Aborto e ativismo religioso nas eleições de 2010. Revista Brasileira de Ciência Política (Brasília), 3(7), 25-54. doi:10.1590/S0103-33522012000100003

Maingueneau, D. (1997). Novas tendências em análise do discurso (3. ed.). Campinas, SP: Pontes.

Maingueneau, D. (2006). Cenas da enunciação. Curitiba, PR: Criar Edições.

Malta, M. (2013). Frente em Defesa da Família luta para melhorar mudanças no Código Penal. Recuperado em http://www.magnomalta. com/portal2/index.php/outras-notas-mainmenu-45/2886-frente-em-defesa-da-familia-luta-para-melhorar-mudancas-no-codigo-penal

Marcello, M. C. (2012, 12 abr.). STF aprova legalização de aborto de anencéfalo. Recuperado em http://br.reuters.com/article/topNews/idBRSPE83C00420120413

Mikael-Silva, T., \& Martins, A. M. (2015). A legalização do aborto no Brasil ao longo da história: Avanços e desafios. Revista Venezolana de 
Estudios de la Mujer, 20, 197-214. Recuperado em http://saber.ucv.ve/ojs/index.php/rev_vem/ issue/view/1090/showToc

Ministério da Saúde. (2009). Guia de vigilância epidemiológica do óbito materno. Brasília, DF: Autor.

Movimento critica projetos contrários a interesses femininos. (2011, 18 ago.). Folha de São Paulo. Recuperado em http://www1.folha.uol.com. $\mathrm{br} /$ multimidia/podcasts/2011/08/961772-movimento-critica-projetos-contrarios-a-interessesfemininos.shtml

Movimento Nacional da Cidadania pela Vida Brasil Sem Aborto. (2011). Café da Manhã com parlamentares pró-vida. Recuperado em http://www.brasilsemaborto.com.br/index. php? action $=$ noticia\&idn noticia $=116 \& \mathrm{cac}$ he $=0.0652514745015651$

Pinho, A. A. (2009). Os debates sobre o aborto na mídia brasileira: Dos enquadramentos midiáticos a construção de uma democracia plural. $E$ -cadernos CES, 135-156. doi:10.4000/eces.233

Pinto, T. F. (2013). Aborto no Brasil atual: Entre o direito e as políticas públicas. Revista Brasileira de Políticas Públicas, 3(1), 13-24. Recuperado em http://www.publicacoesacademicas.uniceub. br/index.php/RBPP/article/view/1951

Pires, T. I. T. (2013). Estado democrático de direito e as liberdades individuais: A legalização do aborto à luz do princípio da autodeterminação. Revista da Faculdade de Direito UFPR, 58, 125-145. doi:10.5380/rfdufpr.v58i0.34868

Rodrigues, E. B. de S. (2012, fev.). Artigos dos Bispos: Crack, aborto e ideologias. Conferência Nacional dos Bispos do Brasil. Recuperado em http:// www.cnbb.org.br/index.php?option=com conte nt\&view=article \&id=8853:crack-aborto-e-ideologia- $\&$ catid $=314 \&$ Itemid $=204$

Rodrigues, F. (2014, 14 jun.). Eleições 2014: Leia a transcrição da entrevista de Eduardo Jorge à Folha e ao UOL. Folha de São Paulo. Recuperado em http://www1.folha.uol.com.br/poder/ poderepolitica/2014/06/1470402-leia-a-transcricao-da-entrevista-de-eduardo-jorge-a-folha-e-ao-uol.shtml
Sagan, C. (1998). Bilhões e bilhões na virada do milênio. São Paulo, SP: Companhia das Letras.

Senado Federal. (2011). Movimento de mulheres critica projetos de lei contrários a interesses femininos. Portal de Notícias. Recuperado em http://www 12.senado.leg.br/noticias/materias/2011/08/18/movimento-de-mulheres-critica-projetos-de-lei-contrarios-a-interesses-femininos

Senado Federal. (2013). Proposta de novo Código Penal é mais rigorosa com progressões de pena. Recuperado em http://www12.senado.leg.br/ noticias/materias/2013/12/10/proposta-de-novocodigo-penal-e-mais-rigorosa-com-progressoesde-pena

Soares, G. S., Galli, B., \& Viana, A. P. A. L. (2011). Advocacy para o acesso ao aborto legal e seguro: Semelhanças no impacto da ilegalidade na saúde das mulheres e nos serviços de saúde em Pernambuco, Bahia, Paraíba, Mato Grosso do Sul e Rio de Janeiro. Recife, PE: Grupo Curumim.

Taques, P. (2013). Parecer da Comissão Temporária de Estudo da Reforma do Código Penal sobre o Projeto de Lei do Senado $n^{\circ} 236$, de 2012, que reforma o Código Penal Brasileiro, e proposições anexadas. Brasília, DF.

Valpassos, C. A. M. (2011). Abortos e histórias sobre eles (Tese de doutorado, Universidade Federal do Rio de Janeiro, RJ, Brasil).
Recebido: 20/03/2015

$1^{a}$ revisão: $25 / 08 / 2015$

Aceite final: 31/08/2015 